\title{
Politique
}

Politique

\section{Pour une politique, le programme de la Révolution tranquille de Georges-Émile Lapalme, préface de Claude Corbo, Montréal, VLB éditeur et Maria Lapalme, 1988, 353 p.}

\section{Danielle Savard}

Numéro 20, automne 1991

URI : https://id.erudit.org/iderudit/040708ar

DOI : https://doi.org/10.7202/040708ar

Aller au sommaire du numéro

Éditeur(s)

Société québécoise de science politique

ISSN

0711-608X (imprimé)

1918-6584 (numérique)

Découvrir la revue

Citer ce compte rendu

Savard, D. (1991). Compte rendu de [Pour une politique, le programme de la Révolution tranquille de Georges-Émile Lapalme, préface de Claude Corbo, Montréal, VLB éditeur et Maria Lapalme, 1988, 353 p.] Politique, (20), 177-179. https://doi.org/10.7202/040708ar d'utilisation que vous pouvez consulter en ligne.

https://apropos.erudit.org/fr/usagers/politique-dutilisation/ 


\section{Pour une politique,}

\section{le programme de la Révolution tranquille}

de Georges-Émile Lapalme, préface de Claude Corbo, Montréal, VLB éditeur \& Maria Lapalme, 1988, 353 p.

Cet essai de Georges-Émile Lapalme, Pour une politique, écrit durant l'été 1959, nous transporte sans ambages dans le contexte politique du Québec au moment où il allait prendre le virage de la Révolution tranquille. Cette publication, à titre posthume, et près de $\mathbf{3 0}$ ans suivant sa rédaction, veut en quelque sorte réparer une injustice et rendre les honneurs a Georges-Émile Lapalme qui a su innover et doter le Parti libéral de 1960 d'un projet de société encore d'actualité aujourd'hui.

La notice biographique de Georges-Emile Lapalme, inspirée de ses Mémoires et présentée par Michel Lapalme, est par ailleurs très instructive sur l'homme et ses réalisations (p. 18-26). Homme de lettres et de culture autant que politicien, il ouvre à 21 ans une étude d'avocat à Joliette. Opposé au règne de Duplessis, il est élu chef du Parti libéral en 1950. Dès lors, il entreprend deux tâches : I'organisation du parti et la diffusion du programme. Pour une politique est une synthèse de I'histoire et des débats du Parti libéral des années 50 jusqu'à la mort de Duplessis. Rédigée l'été précédant la mort de ce dernier, c'est la version abrégée de cet essai de Georges-Émile Lapalme qui devient le programme du Parti libéral sous le titre de "Lesage s'engage" (p. 23-24). Georges-Émile Lapalme est rélu dans Outremont et nommé ministre de la Justice. En avril 1961, c'est la création du ministère des Affaires culturelles et Georges-Émile Lapalme en devient le premier titulaire; il étend les contacts entre la France et le Québec. En 1964, Georges-Émile Lapalme démissionne après vingt ans de politique. Durant les années qui suivirent, il fut commissaire de Terre des Hommes, juge à la Cour de la citoyenneté, président de la Société canadienne de développement de l'industrie du cinéma et président de la Commission des biens culturels. Georges-Émile Lapalme est décédé à l'âge de 78 ans, le 5 février 1985. 
Monsieur Claude Corbo, dans la préface (p. 9-14), précise que Georges-Émile Lapalme ne voulait pas qu'un ouvrage imparfait soit lu par d'autres personnes que celles qui l'utilisèrent dans les semaines et les mois qui suivirent. Sa rédaction met en valeur sa contribution a la Révolution tranquille.

L'essai rédigé par Georges-Émile Lapalme se compose de deux livres. A la fin de chacun d'eux se retrouvent des annexes référant à des articles, à des recherches, ainsi qu'une entrevue intégrale accordée au journal Le Devoir, le 24 mai 1952. A la fin des deux annexes, l'éditeur a reproduit deux brochures dont le texte est inspiré de Pour une politique : il s'agit du programme du Parti libéral de 1960 et du manifeste électoral de 1962. S'ajoute à cela le discours de M. GeorgesÉmile Lapalme au $5^{\circ}$ congrès de la Fédération libérale du Québec, tenu à Québec les 16 et 17 octobre 1959.

Georges-Émile Lapalme, dans son essai Pour une politique, propose un remaniement complet de l'organisation politique du Québec des années 50 . II s'attaque à tous les champs de la politique québécoise pour en reconstruire les fondements. De l'exclusion à l'immobilisme où était plongé le Québec sous le long règne de Duplessis, Georges-Émile Lapalme repense la politique et tourne la province vers l'avenir. Pour lui, la province de Québec en devenir doit sortir du marasme et de l'ignorance afin de permettre au peuple de trouver son identité et de s'affirmer sur les scènes nationales et internationales. Les Canadiens français doivent donc développer une culture intellectuelle et artistique attrayante et compétente qui se reflétera dans le paysage urbain réaménagé. La province doit aussi garder sous contrôle les ressources naturelles de son territoire.

Suivant cette perspective, la réforme proposée verra a améliorer globalement les conditions de vie des citoyens en instaurant la gratuité de l'éducation et des soins de santé, en édifiant un code du travail conçu en fonction des travailleurs et en prônant le droit à tout électeur d'être élu avec le consentement de ses pairs. 
Concernant les régions et les municipalités, il suggère de restructurer tout le visage urbain avec une voirie organisée. La conservation des habitations ancestrales typiques du patrimoine, l'innovation d'un réseau d'auberges gastronomiques de même que les créations artistiques peuvent faire partie du paysage et, ainsi, attirer les touristes (p. 143).

Concernant l'appareil gouvernemental, il propose la création de ministères responsables de la gestion des nouveaux services (Éducation, Santé, Affaires culturelles, Richesses naturelles, etc.). II propose aussi que la province se donne le mandat, sur le plan national, de négocier avec les autres provinces une modification ou un changement de la constitution qui respecterait, par exemple, les deux langues officielles (p. 275). Par ailleurs, le Gouvernement devrait aussi réfléchir sur la situation du Québec à l'intérieur d'échanges internationaux.

Somme toute, Georges-Émile Lapalme avait foi en l'émancipation globale du Québec. Le slogan «Maîtres chez nous» du programme de la campagne libérale du 22 juin 1960 résume les objectifs proposés par Georges-Émile Lapalme et l'envergure du travail a faire pour le Parti libéral, élu sous la direction de Jean Lesage.

Pour une politique est, dans un sens, un livre d'intérêt pour toutes les personnes passionnées ou curieuses de notre histoire politique, économique et sociale, car le contenu dépasse de beaucoup ce que nous pouvons en dire.

En effet, ce livre nous laisse dans un état de fierté mais en même temps d'amertume. Quelque trente années plus tard, dans le contexte de réformes actuelles (Santé, Éducation, etc.) émergera-t-il un groupe capable de penser globalement et justement (même si ce n'est qu'idéologiquement) l'ensemble de la politique québécoise des années 90? Un tel projet de société est-il possible aujourd'hui?

Danielle Savard 